Seção especial - Territorialización de la agroecología

Vol. 58, p. 509-530, jul./dez. 2021. DOI: 10.5380/dma.v58i0.81339. e-ISSN 2176-9109

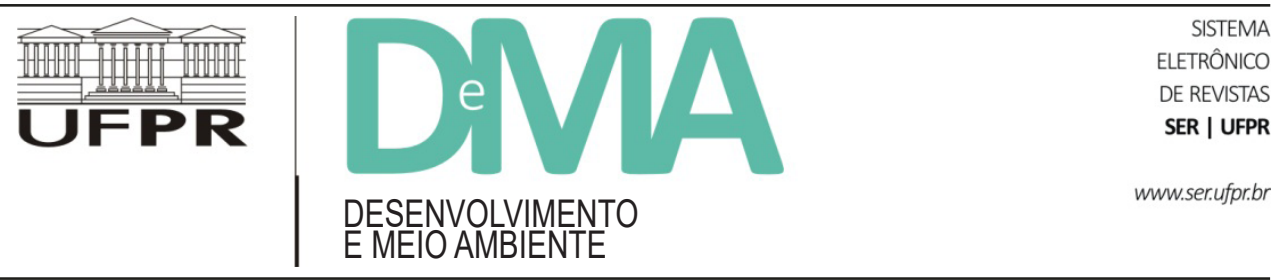

\title{
Agroecología y La Vía Campesina I. La construcción simbólica y material de la agroecología a través de los procesos de "campesina(0) a campesina(0)"1
}

\section{Agroecologia e a Via Campesina I. A construção simbólica e material da} agroecologia através dos processos de "camponês(a) a camponês(a)"

\section{Agroecology and La Vía Campesina I. The symbolic and material construction of agroecology through "peasant-to-peasant" processes}

Valentín VAL ${ }^{1 *}$, Peter ROSSET ${ }^{1,2,3,4}$, Carla ZAMORA LOMELI' ${ }^{1}$, Omar Felipe GIRALDO ${ }^{1,5}$, Dianne ROCHELEAU ${ }^{6}$

${ }^{1}$ El Colegio de la Frontera Sur (ECOSUR), San Cristóbal de Las Casas, Chiapas, México.

${ }^{2}$ Profesor BPV-FUNCAP del Programa de Pós-Graduação em Sociologia (PPGS), Universidade Estadual do Ceará (UECE), Fortaleza, CE, Brasil.

${ }^{3}$ Profesor Colaborador del Programa de Pós-Graduação em Desenvolvimento Territorial na América Latina e Caribe (TerritoriAL), Universidade Paulista (UNESP), São Paulo, SP, Brasil.

${ }^{4}$ Profesor visitante, Social Research Institute (CUSRI), Chulalongkorn University (Chula), Bangkok, Tailandia.

${ }^{5}$ Universidad Nacional Autónoma de México (UNAM), Escuela Nacional de Estudios Superiores (ENES), Mérida, Yucatán, México.

${ }^{6}$ Clark University, Worcester, MA, EUA.

*E-mail de contacto: vaval@ecosur.edu.mx

Artículo recibido en 4 de junio de 2021, publicado en 30 de noviembre de 2021.

\footnotetext{
1 Este artículo fue publicado originalmente en inglés en: Val, V.; Rosset, P. M.; Zamora Lomelí, C. Giraldo, O. F.; Rocheleau, D. Agroecology and La Via Campesina I. The symbolic and material construction of agroecology through the dispositive of "peasant-to-peasant" processes. Agroecology and Sustainable Food Systems, 43(7-8), 872-894, 2019.
} 
RESUMEN: En este ensayo abordamos la territorialización simbólica y material de la agroecología en La Vía Campesina (LVC) a través de procesos de campesina(o) a campesina(o) (PCaC) en sentido amplio. Los ejemplos de masificación de la agroecología más significativos están claramente ligados a procesos organizativos y, desde nuestra perspectiva, el corazón de esos avances son los PCaC. Sostenemos que allí se articulan agroecologías, sujetos y territorios, constituyendo un potente dispositivo para la transformación agroecológica. También introducimos la discusión sobre la constitución de un sujeto histórico-político, el "campesinado agroecológico" para la disputa territorial por la transformación del sistema agroalimentario y las condiciones de vida en el campo.

Palabras clave: La Vía Campesina; procesos de campesina(o) a campesina(o); dispositivo; agroecología; masificación.

RESUMO: Neste ensaio abordamos a territorialização simbólica e material da agroecologia na Via Campesina (LVC) através de "Processos de Camponês(a) a Camponês(a)" (PCaC) num sentido lato. Os exemplos mais significativos da expansão da agroecologia estão claramente ligados a processos organizacionais e, na nossa perspectiva, o motor destes avanços é a PCaC. Sustentamos que é aqui que se articulam as agroecologias, temas e territórios, constituindo um poderoso dispositivo de transformação agroecológica. Introduzimos também a discussão sobre a constituição de um tema histórico-político, o "campesinato agro-ecológico" para a disputa territorial pela transformação do sistema agro-alimentar e as condições de vida no campo.

Palavras-chave: La Vía Campesina; processos de camponês(a) a camponês(a) (PCaC); dispositivo; agroecologia; massificação.

ABSTRACT: In this essay, we look at the symbolic and material territorialization of agroecology in La Vía Campesina (LVC) through peasant-to-peasant processes (PtPPs) in the broad sense. The most significant examples of the scaling up of agroecology are clearly tied to organizational processes and in our perspective, PtPPs are the motor of these changes. We contend that agroecology, subjects, and territories are articulated in these processes, making up a powerful dispositive or device for agroecological transformation and scaling up. We also introduce a discussion on the emergence of a historical-political subject, the "agroecological peasantry," within the larger territorial dispute concerning the transformation of the agri-food system and living conditions in the countryside.

Keywords: La Vía Campesina; peasant-to-peasant process; dispositive; agroecology; scaling up.

\section{Introducción}

Este es el primero de dos artículos en los que abordamos de manera conceptual diferentes estrategias y dispositivos para el escalamiento y masificación de la agroecología dentro de $\mathrm{La}$ Vía Campesina Internacional (LVC). Delineamos aquí las primeras ideas en torno a la construcción de los procesos de campesina(o) a campesina(o) $(\mathrm{PCaC})$ como un dispositivo ${ }^{2}$ para la masificación y transformación agroecológica, la movilización de un proyecto político campesino y la constitución de un sujeto histórico-político dentro del universo de organizaciones vinculadas a LVC. En este texto

\footnotetext{
${ }^{2}$ En el sentido desarrollado por Foucault (1992; 2000) y comentado por Bussolini (2010) y García Fanlo (2011).
} 
describimos el dispositivo conceptualmente, en tanto que en otro trabajo nos enfocamos en los procesos político-pedagógicos en agroecología dentro de LVC como dispositivo específico (véase Rosset et al., en este mismo volumen).

Este artículo se basa fundamentalmente en los aportes del movimiento agroecológico de la Asociación Nacional de Agricultores Pequeños (ANAP) de Cuba por ser paradigmático en términos de masificación de la agroecología, a la vez que un referente central en los procesos que se desarrollan en LVC (Machín Sosa et al., 2010; Rosset et al., 2011; Val, 2012; LVC, 2012; 2016). Para contextualizar esta propuesta, primero describimos el contexto de llegada de la metodología CaC a Cuba, y cómo se fue reconfigurando en un dispositivo de ensamblaje de agroecologías, territorios y sujetos. Enseguida nos ocupamos de ese dispositivo propiamente y de lo que constituye su aporte principal. En tercer lugar discutimos la importancia de los $\mathrm{PCaC}$, así como la emergencia de un sujeto histórico-político, es decir, el campesinado agroecológico, para la materialización del proyecto político de la LVC. Argumentamos que estos procesos configuran una potente estrategia para la masificación de la agroecología.

Al hablar de masificación, nos referimos tanto a la dimensión cuantitativa más ampliamente admitida -incorporar cada vez más personas, comunidades y organizaciones a la agroecología-, como a la dimensión cualitativa de los procesos de organización, transmisión y consolidación de la agroecología como forma de vida en territorios concretos (Holt-Giménez, 2001; Gonsalves, 2001; Parmentier, 2014; Brescia, 2017; Rosset \& Altieri, 2017; Gliessman, 2018). En este texto, masificación no significa una reproducción lineal de patrones preconcebidos ni tomar algo pequeño y volverlo grande, sino más bien potenciar y multiplicar muchos pequeños procesos (Rosset, 2015).

Desde nuestra perspectiva, la clave de la potencia masificadora de los $\mathrm{PCaC}$ radica en el balance entre organización y espontaneidad, en la articulación entre estructuras jerárquicas y horizontales, y en la capacidad de generar marcos de referencia y redes sin imponer modelos únicos. Es decir, se trata de un diseño en red capaz de autoorganizarse y crear procesos emergentes de (re)territorialización agroecológica. No hablamos de procesos linealmente replicables, sino que en cada territorio se dan procesos endógenos, cultural y ambientalmente únicos y adecuados. Procesos articulados, con cooperación y solidaridad, pero sin imposición ni moldes preestablecidos (Rosset, 2015; Giraldo, 2018).

Los ejemplos de masificación de la agroecología más significativos están claramente ligados a procesos organizativos (De Schutter, 2010; Rosset \& Altieri, 2017; Mier y Terán et al., 2018). Los procesos de protagonismo campesino son esenciales para impulsar el escalamiento de la agroecología y, para incorporar más personas y territorios al movimiento agroecológico, resulta imprescindible trabajar en pro del fortalecimiento de las organizaciones campesinas en el desarrollo de sus propios procesos sociales, territoriales y políticos (Rosset, 2015). En este sentido, los procesos de $\mathrm{CaC}$ son medulares en la estrategia de masificación de la agroecología en LVC.

En líneas generales, cuando se piensa en campesina(o) a campesina(o), la referencia más inmediata suele ser la metodología de transmisión horizontal de conocimientos técnico-productivos. Una metodología participativa en la que se aspira 
a romper con el verticalismo, las relaciones de saber-poder y la dependencia de expertos; un proceso donde los actores son coproductores de conocimientos a través del intercambio de ideas, experiencias e innovaciones en la producción agroecológica (CaC stricto sensu) (Holt-Giménez, 2006; Kohlmans, 2006). En estas formas de enseñanza-aprendizaje, se aprende haciendo "en el surco"; desde la finca como espacio privilegiado de formación, capacitación y experimentación. Las innovaciones y experiencias exitosas se sistematizan colectivamente y sirven como ejemplo para que otros se motiven y se fortalezca y expanda la producción agroecológica (Vásquez Zeledon \& Rivas Espinosa, 2006; Machín Sosa et al., 2010; Val, 2012).

Estos procesos suelen estar vinculados a otros campos de formación como las Escuelas Campesinas (Barbosa, 2013; McCune et al., 2014; 2016; Barbosa \& Rosset, 2017; también Khadse \& Rosset, Rosset et al., y Domené et al., en este mismo volumen); espacios de organización y articulación política locales, nacionales e internacionales (encuentros, eventos, talleres, etcétera); procesos de cooperación Sur-Sur y "de organización campesina a organización campesina" (Rosset et al., 2011). En todos esos espacios se desarrollan diferentes procesos de articulación e intercambios que globalmente podemos denominar Procesos de Campesina(o) a Campesina(o) (PCaC). Este último será el sentido al que haremos referencia al hablar de campesina(o) a campesina(o) a lo largo de este texto.

En un artículo anterior de nuestro grupo de investigación (Mier y Terán et al., 2018) se han identificado ocho factores clave que detonan los procesos para el escalamiento de la agroecología en diferentes contextos: 1) existencia de una crisis que impulsa la búsqueda de alternativas; 2) organización social; 3) procesos de aprendizaje constructivista; 4) prácticas agroecológicas efectivas; 5) discursos movilizadores; 6) aliados externos; 7) mercados favorables, y 8) políticas favorables.

Entendidos en sentido amplio, los $\mathrm{PCaC}$ incluyen, en mayor o menor medida, todos los factores clave identificados en el párrafo previo. El surgimiento mismo de los procesos CaC está asociado a la búsqueda de alternativas ante la crisis (factor 1); organizándose para compartir prácticas agroecológicas efectivas desde un modelo horizontal (factores 2, 3 y 4); generando discursos movilizadores y articulando alianzas (factores 5 y 6); diseñando y organizando estrategias con las(os) consumidoras(es) (factor 7); y delineando, demandando y/o efectivizando políticas públicas favorables (factor 8). En este trabajo nos centraremos en cómo estos factores se ensamblan, articulan y retroalimentan en los $\mathrm{PCaC}$.

Otras experiencias donde consideramos que los $\mathrm{PCaC}$ son importantes se abordan desde perspectivas diferentes en este mismo volumen, en concreto, en los trabajos sobre escuelas y procesos formativos en agroecología: Rosset et al.; Khadse \& Rosset; Domené et al.; Aldasoro et al.; Morales y Ferguson; y otros procesos organizativos como los de recuperación y el fortalecimiento de los sistemas locales de semillas (García et al.), los mercados campesinos (Pérez \& Mier y Terán) y las políticas públicas (Giraldo \& McCune). 


\section{Campesina(o) a Campesina(o). De metodología a dispositivo}

Campesina(o) a Campesina(o) $(\mathrm{CaC})$ dio sus primeros pasos en Guatemala, México y Nicaragua (Ramos, 1998; Holt-Giménez, 2006; Boege \& Carranza, 2009). Pero fue en 1996 que un dirigente de la ANAP de Cuba la "descubrió" en Nicaragua, advirtió su potencial catalizador y se entusiasmó con la posibilidad de incorporarla al incipiente proceso agroecológico cubano (Machín Sosa et al., 2010). El desarrollo de la agroecología en Cuba estuvo estrechamente ligada a la profunda crisis agroalimentaria conocida popularmente como el "Período Especial en Tiempos de Paz" a inicios de la década de los 1990. La caída del campo socialista significó para Cuba la pérdida del $85 \%$ de sus mercados y el fin repentino del abasto de petróleo, maquinarias y alimentos a precios subsidiados (Figueras Matos et al., 2005; González Mastrapa \& Susset Pérez, 2010; Doimeadios Reyes, 2011).

En el campo, el modelo convencional tipo "revolución verde" de alta dependencia de insumos provistos por la Unión Soviética colapsó y la producción agrícola a gran escala quedó paralizada. Ante este panorama, se observó que había un sector de la población rural que no se vio mayormente afectado en sus producciones. Así, el "campesinado tradicional" se volvió el foco de una reconversión forzada del modelo de producción agroalimentaria (Figueras Matos,
2005; Machín Sosa et al., 2010). Esta transición hacia una agricultura de pequeña escala ${ }^{3}$, basada en tecnologías tradicionales campesinas, sin insumos externos, e incorporando principios productivos agroecológicos, fue promovida y motorizada por la ANAP, en articulación con universidades, centros de investigación, instituciones gubernamentales y ONG (Machín Sosa et al., 2010; Val, 2012).

Fue en ese marco que la ANAP recogió de Nicaragua la metodología CaC. En 1997 inició en la provincia de Villa Clara un pequeño proyecto para la adaptación y transformación agroecológica de la producción agroalimentaria ${ }^{4}$. Dos años después, el proyecto se extendió como programa a toda la región central, abarcando además las provincias de Sancti Spíritus y Cienfuegos (Figueras Matos, 2005; Machín Sosa et al., 2010). El impacto positivo de esta metodología y la recuperación de la productividad en las fincas insertadas, llevaron a que la ANAP decidiera convertir el programa en un movimiento de masas a nivel nacional. Así surgió, en el año 2001, el "Movimiento Agroecológico de Campesino a Campesino (MACAC)" (Machín Sosa et al., 2010; Rosset et al., 2011; Val, 2012).

El MACAC se basa en la emulación, es una "pedagogía de la experiencia" (Barbosa y Rosset 2017) donde una familia campesina visita a otra que haya encontrado una solución agroecológica adecuada a un problema común, por lo que intercambian experiencias, aprenden mutuamente y fortalecen el conocimiento de ambas en el encuentro

\footnotetext{
${ }^{3}$ Las grandes granjas y otras tierras de propiedad estatal fueron parceladas y repartidas en usufructo entre numerosos productores organizados en diferentes tipos de asociación cooperativa, en un nuevo proceso de reforma agraria que continúa hasta el presente (Pérez Rojas \& Echeverría León, 1998; Merlet, 2011).

${ }^{4}$ El Programa Productivo de Promoción Agroecológica (PPPA) inició en la provincia de Villa Clara, con 13 facilitadores (uno por municipio) y 27 promotoras(es), campesinos(as) que desde sus propias fincas y experiencias divulgaban y promocionaban la agroecología (Figueras Matos, 2005).
} 
(Machín Sosa et al., 2010; Val, 2012). El objetivo central es la construcción de procesos territoriales que permiten masificar la agroecología, en el sentido de incorporar muchas familias a una producción agrícola de matriz agroecológica, con una expansión territorial y de sujetos en ese tipo de praxis (Machín Sosa et al., 2010; Rosset et al., 2011; Rosset, 2015).

En sus más de veinte años de existencia, el movimiento agroecológico ha ido creciendo en dimensión e importancia al interior de la ANAP, a tal punto que en la actualidad es central para su concepción de producción campesina. De un poco más de 200 familias en 1999, el movimiento creció a 110,000 familias diez años después, de forma que hoy representa aproximadamente un tercio del sector campesino cubano (Machín Sosa et al., 2010). Para 2009 el movimiento ya contaba con una sólida estructura en los diferentes niveles (cooperativa, municipal, provincial y nacional), y contaba con unos 27,000 promotores, 3,500 facilitadores y 170 coordinadores agroecológicos (ANAP, 2020). En la actualidad se estima que 170,000 campesinos, casi la mitad del total cubano participa en el MACAC (ANAP, 2020), y el impacto es aún mayor si se considera el efecto indirecto sobre las familias que no participan formalmente, pero que han incorporado algunas prácticas agroecológicas (Rosset \& Val, 2018).
La experiencia organizativa del MACAC cubano es promovida entre las organizaciones de LVC como ejemplo exitoso para el escalamiento y masificación de la agroecología (Machín Sosa et al., 2010; Rosset et al., 2011; Val, 2012; Rosset \& Val, 2018). Mientras que la ANAP, a través de la CLOC-VC, ejerce un amplio internacionalismo campesino colaborando con numerosas organizaciones campesinas en América Latina y el mundo. Además, LVC planea para las organizaciones miembros visitas regulares a Cuba para participar de encuentros, intercambios de experiencias y procesos formativos en el Centro de Formación Integral "Niceto Pérez García", la escuela de capacitación de la ANAP5. Entre los cursos más demandados se encuentra el taller de metodología $\mathrm{CaC}$, donde la ANAP comparte sus logros, desafíos e innovaciones en la constitución del MACAC y la masificación de la agroecología en Cuba (Machín Sosa et al., 2010; LVC, 2015; 2018) ${ }^{6}$.

Agroecología y $\mathrm{CaC}$ fueron redefinidos y resignificados en clave cubana, en un proceso sui generis. La metodología $\mathrm{CaC}$ se combinó con las tácticas y formas de organización de los movimientos sociales de base, resultando en un movimiento dinámico, de gran organicidad y con una estrategia precisa para la masificación de la agroecología. Un movimiento políticamente articulado con organizaciones campesinas latinoamericanas e

\footnotetext{
${ }^{5}$ No es casual que Cuba se haya convertido en un referente de las organizaciones y luchas campesinas (y de muchas otras) de carácter antiimperialista y anticapitalista. Este país se ha constituido en un modelo tanto por la construcción efectiva de alternativas contrahegemónicas, como por el simbolismo y la legitimidad moral del proceso revolucionario cubano para los movimientos sociales populares que buscan la transformación del orden socioeconómico imperante. En este sentido, la escuela de la ANAP ha sido históricamente un espacio importantísimo para la formación de militantes, cuadros y dirigencias de organizaciones campesinas de todo el mundo, especialmente de América Latina y África.

${ }^{6}$ Basados en la observación participante de dos de los autores de este texto (Rosset \& Val), podemos afirmar que en el ámbito de la CLOC, la experiencia está emulándose en Brasil, Colombia, Chile, Guatemala, Nicaragua, Paraguay, Puerto Rico y Venezuela, principalmente. En los últimos años su influencia se ha extendido hacia otras regiones, iniciándose diferentes procesos de CaC en Asia del Sur (India, Sri Lanka, Nepal) y Asia Pacífico (Filipinas, Indonesia, Tailandia, Corea); África (RD del Congo, Ghana, Mali, Mozambique, Zimbabue); y Europa (Bélgica, Estado Español, Francia, Noruega, Reino Unido).
} 
internacionales que sostienen la transformación de los sistemas agroalimentarios y la justicia social y ambiental como banderas de lucha. La construcción de la soberanía alimentaria, la estrategia global de defensa de los territorios, las semillas y los bienes comunes, son algunos ejemplos de esa articulación (Machín Sosa et al., 2010; Rosset, 2013; MartínezTorres \& Rosset, 2014; Val, 2012; 2017).

La innovación cubana ha ido reconfigurando $\mathrm{CaC}$ como un complejo dispositivo multidimensional de ensamblaje de agroecología(s), territorio(s) y Sujeto(s). Señalamos con los paréntesis que existen heterogéneas concepciones de agroecología que pueden emerger y (re)configurarse en este dispositivo; que articula tanto una territorialidad local (material e inmaterial), como diferentes territorios y territorialidades; y que interviene en la constitución de sujetos campesinos locales, a la vez que en la emergencia de un meta-sujeto campesino global: el campesinado agroecológico.

Entendemos dispositivo como mecanismo de poder -alterno, contrahegemónico- desarrollado para contrarrestar las tecnologías de poder y las estructuras de opresión de la sociedad disciplinaria (Foucault, 1992; 2000), hoy transformadas en sociedades de control (Deleuze, 2006); también como mecanismo de ensamblaje multidimensional de diferentes prácticas, discursos y representaciones interrelacionadas que se ponen en juego para una determinada acción colectiva (Tilly, 1978; Svampa, 2009; Zamora, 2014).

Hablamos aquí de $\mathrm{CaC}$ como un dispositivo flexible, en tanto constelación de conceptos/acciones/ posibilidades que se unen por una suerte de "fuerza de gravedad", pero sin tener un centro gravitatorio único, sino que se mueven en una dinámica relacional de gravedad policéntrica. A esas diferentes fuerzas complementarias que cohesionan el dispositivo las hemos denominado vectores. Para presentar este complejo dispositivo haremos foco en tres vectores fundamentales: 1) como dispositivo de ensamblaje de agroecologías; 2) en la creación y articulación de territorios; y 3) el rol de $\mathrm{CaC}$ en la emergencia del sujeto campesino. La separación en vectores es una representación estilizada con fines analíticos; en la práctica, estas dimensiones se interrelacionan e imbrican permanentemente y resulta difícil delimitar las fronteras entre unos y otros (ver Figura 1).

\section{Vector 1: dispositivo de ensamblaje de agroecología(s)}

Este vector contiene, en líneas generales, los aspectos más conocidos de $\mathrm{CaC}$ stricto sensu. Es decir, como proceso horizontal de formación y promoción colectiva de la agroecología; y como un espacio-tiempo de interacción alterno en términos ontológicos, epistémicos y filosóficos desde donde emergen y se (re)significan saberes, prácticas y discursos que nutren el concepto de agroecología.

Nos enfocaremos aquí en $\mathrm{CaC}$ en tanto mecanismo de ensamblaje de las diferentes dimensiones de la agroecología, articulando lo técnico-productivo, lo político-ideológico y lo ontológico-epistémico-vivencial. Proceso donde se construye y legitima la agroecología como un campo de posibilidades de existencia para los modos de vida campesinos. Una actualización al siglo XXI de la agri-cultura como forma de producción y de vida (Giraldo, 2018).

Agroecología es un término polisémico que se encuentra en disputa (Giraldo \& Rosset, 2018). En determinados contextos, la agroecología se 


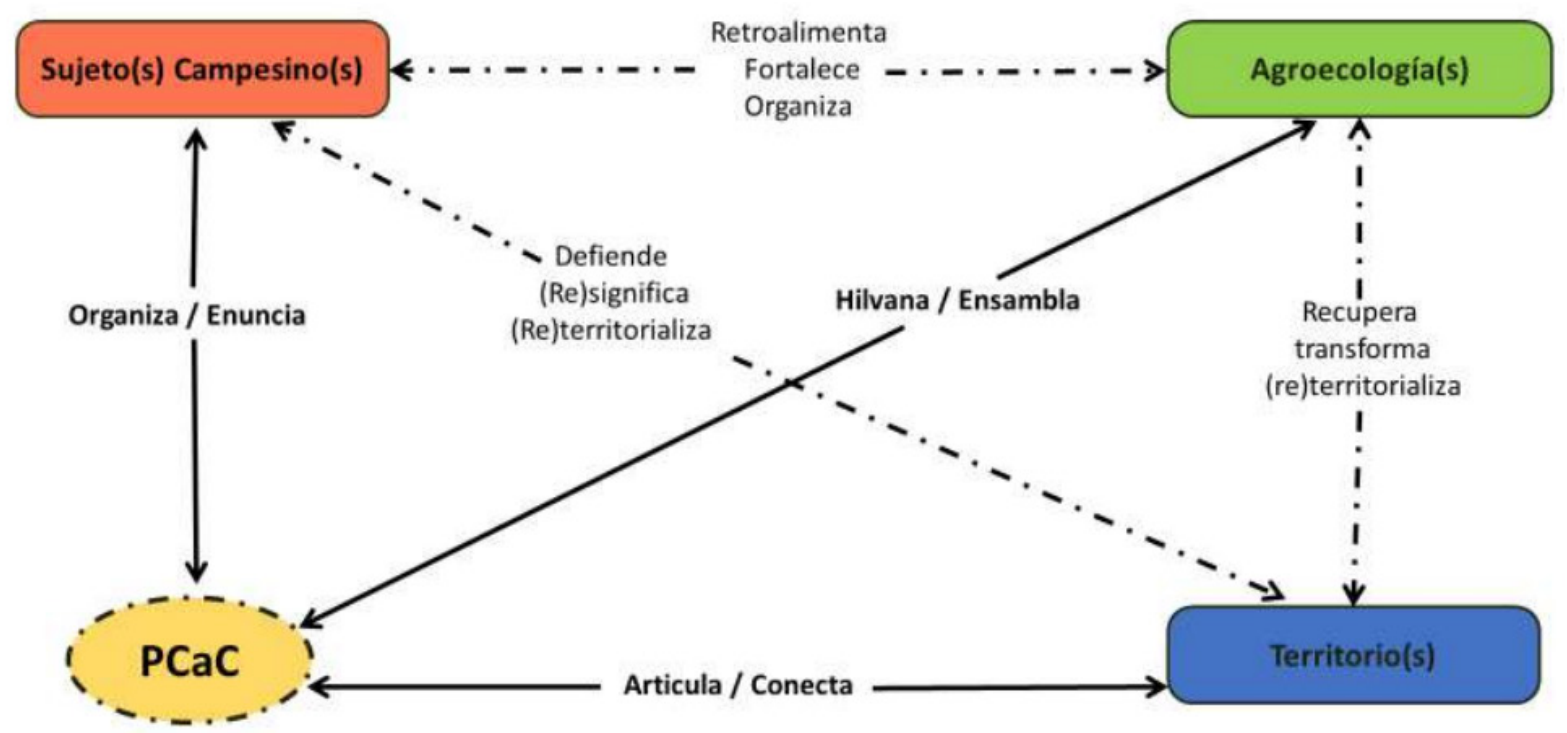

FIGURA 1 - Los 3 vectores en el funcionamiento de los PCaC como dispositivo de ensamblaje.

concibe como una serie de principios-guía para la producción agroalimentaria de base ecológica, pero sin la utilización de insumos externos al sistema (Rosset \& Altieri, 2017). Es un término que se refiere a la conformación, dinámicas, transformación y manejo de los agroecosistemas en torno a las producciones familiares de pequeña escala (campesinas e indígenas), mediante la integración de conocimientos locales, prácticas tradicionales e innovaciones tecnológicas?

La agroecología como propuesta analítica se relaciona con la ecología cultural y su heredera contemporánea, la ecología política. Se nutre de los debates posmodernos y la crítica decolonial, y plantea nuevas perspectivas en la conceptualización de las relaciones entre seres humanos y naturaleza (Sevilla Guzmán, 2006; Calle Collado \& Gallar,
2010; Giraldo, 2018). Por otra parte, numerosas organizaciones campesinas y movimientos sociales rurales conceptualizan la agroecología más allá de los principios técnico-productivos, incorporando principios sociales, culturales y políticos (Calle Collado \& Gallar, 2010; Machín Sosa et al., 2010; Rosset \& Martínez-Torres, 2016). Por tanto, podríamos decir que la agroecología tiene al menos tres dimensiones fundamentales íntimamente relacionadas e imbricadas:

1. La técnico-productiva: agronómica, científica y como campo disciplinar; la "agroecología material" o "agroecology as farming" (Rosset \& Martínez-Torres, 2012);

\footnotetext{
${ }^{7}$ Para profundizar en el origen, desarrollo y perspectivas de la agroecología, son útiles Altieri (2000), Altieri \& Toledo (2011), Ferguson (2015) y Gliessman $(2007 ; 2015)$, entre otros.
} 
2. La político-organizativa: movilizadora; la "agroecología inmaterial" o "agroecology as framing" (Rosset \& Martínez-Torres, 2012);

3. La ontológico-epistémico-vivencial: cómo modo de ser, conocer, vivir y producir (Da Silva, 2014).

Aquí nos referimos a la agroecología en un sentido integral, como un ensamblaje específico en un espacio-tiempo y realidad concreta en diálogo con escenarios globales. El hacer, vivir y producir local se ensambla con un discurso político más amplio, retroalimentándose mutuamente. La agroecología se convierte entonces en un dispositivo articulador y legitimador de alternativas para los mundos rurales; en un marco de acción política, de subjetividades, representaciones y prácticas alternativas al modelo hegemónico del agronegocio y el proyecto del capital (Desmarais, 2007; Borras et al., 2008; Martínez-Torres \& Rosset, 2008; 2010; 2013). Es una agricultura semánticamente actualizada; la constitución de un devenir campesino particular en el siglo XXI: agroecológico, organizado y contrahegemónico.

\section{Vector 2: la creación y articulación de territorio(s)}

La creación de territorio(s) tiene aquí dos acepciones: por un lado, la creación de territorios desde una territorialidad y (re)territorialización campesina (Haesbaert, 2011; 2013); por otro, la invención (sensu Porto-Gonçalves, 2009) de diferentes territorios inmateriales para la defensa del territorio concreto (Fernandes, 2009; 2017; Rosset \& Martínez-Torres, 2012; Rosset, 2013).
El devenir de los sujetos en el mundo rural ocurre en contextos particulares según la matriz cultural y coordenadas témporo-espaciales. Ese espacio-tiempo es una de las dimensiones del territorio creado, apropiado y significado según la red de relaciones (sociales, con la naturaleza, espirituales, etcétera) en la que estén inmersos los sujetos. Sostenemos aquí, en consonancia con los planteamientos de Escobar (1999; 2005; 2010), que la configuración de los espacios-tiempos campesinos son ontológicamente diferentes, aunque no totalmente ajenos, a los de la modernidad capitalista hegemónica.

La modernidad capitalista produjo un efecto de "desanclaje" al desplazar las relaciones sociales de los contextos locales de interacción, reestructurándolas a través de extensiones indefinidas de espacio-tiempo (Giddens, 1986). Este mismo autor identifica dos mecanismos principales para ese desanclaje: el de las "fichas simbólicas" que circulan sin considerar ambientes específicos, grupos o coyunturas particulares (como el dinero), y el de "los expertos", cuyos conocimientos especializados les permiten usufructuar de manera exclusiva innumerables tecnologías y servicios.

En cierto sentido, $\mathrm{CaC}$ combate estos "mecanismos de desanclaje". Por un lado, los valores centrales son la cooperación y la reciprocidad (ajeno al intercambio monetizado), y por el otro, disputa el mecanismo de los sistemas expertos, ya que el saber-poder se dispersa en diferentes actores y roles dinámicos, rotativos y contextuales. Así, $\mathrm{CaC}$ podría ser entendido como un "mecanismo de reanclaje", recontextualizando las relaciones sociales y (re)creando comunidad desde un espaciotemporal alterno al de las sociedades globalizadas deslocalizadas. 
Giddens (1986) afirma que estamos ante un "estiramiento" de lo local hacia lo global, mientras que Harvey (1998) plantea la compresión del espaciotiempo como condición de la posmodernidad. Estas afirmaciones pueden parecer contradictorias, pero pueden ser entendidas como complementarias y relacionales en el proceso de homogenización del espacio-tiempo de los seres humanos. Las(os) campesinas(os) estarían resignificando y utilizando ese estiramiento de lo global para contener la compresión, y revitalizando el espacio-tiempo local desde la (re)creación de relaciones sociales convivenciales, creando comunidad (Giraldo, 2016). Así, en el proceso de mantener sus espaciostiempos de existencia y no ser avasallados por la globalización, actuarían como fuerzas antagónicas a la inercia homogeneizadora de la modernidad/ posmodernidad capitalista.

Existe una gran disputa por el territorio, desplazamientos y cambios en las relaciones entre seres humanos y naturaleza. Los sujetos producen sus propios territorios, y la destrucción de estos significa el final de aquellos. La desposesión (Harvey, 2004) destruye sujetos, identidades y grupos sociales, por lo que allí se concentra la fuerza de la lucha y la disputa territorial. El territorio está íntimamente relacionado con el poder y con el control de procesos sociales mediante el control del espacio, de modo que la desterritorialización no puede ser disociada de la reterritorialización (Haesbaert, 2013, p. 5).

Desde el fin de la Segunda Guerra Mundial, y más agresivamente en las últimas décadas, las corporaciones transnacionales han expandido a lo largo y ancho del mundo su modelo de desarrollo basado en la apropiación y extracción de los bienes comunes y su transformación en commodities.
Las(os) campesinas(os), indígenas y movimientos sociales rurales han resistido esa expansión porque la territorialización de las transnacionales provoca su desterritorialización (Fernandes, 2009; 2017). A su vez, la resistencia de los movimientos sociales rurales genera multiterritorialidad y promueve la desterritorialización de las transnacionales. Las(os) campesinas(os), las comunidades afrodescendientes e indígenas disputan los territorios basados en sus identidades como requisito de supervivencia (Martínez-Torres \& Rosset, 2010; 2013; Rosset \& Martínez-Torres, 2012; 2016; Fernandes, 2017).

El territorio inmaterial atraviesa todas las dimensiones de lo territorial. Como relación de poder, está vinculado con el control y dominio del proceso de construcción del conocimiento y representaciones (Fernandes, 2017). Entendemos que $\mathrm{CaC}$ es, justamente, un dispositivo de creación y articulación de conocimientos, prácticas y representaciones. Pero no existe, parafraseando a Marx, una separación entre el trabajo intelectual (creación de conceptos) y el manual (las prácticas concretas); tampoco una estructura jerárquica rígida donde se conceptualiza en una superestructura para luego "bajar" a una praxis determinada. Es un proceso dialógico y dialéctico entre conceptualizaciones y prácticas.

Los procesos $\mathrm{CaC}$ actúan como un dispositivo que vincula diferentes saberes, territorios y experiencias a través del intercambio local, nacional e internacional, y contribuyen a la (re) creación y rearticulación de los espacios-tiempos campesinos locales y globales. En el marco del diálogo de saberes, las(os) campesinas(os), militantes, dirigentes y/o intelectuales orgánicos (sensu Gramsci) nominan y enuncian los conceptos que las(os) propias(os) campesinas(os) crean desde sus prácticas y representaciones (Martínez-Torres 
$\&$ Rosset, 2014). En ese sentido $\mathrm{CaC}$ es una de las "cocinas de conceptos" más fructíferas dentro del universo de LVC.

Así, $\mathrm{CaC}$ actúa como un eje transversal que recorre desde los territorios locales (la parcela, la finca, la cooperativa, etcétera) hasta los espacios de macroarticulación como los encuentros promovidos por LVC, procesos de cooperación Sur-Sur y "de organización campesina a organización campesina" (Rosset et al., 2011). Recorre toda la red de micro y macro articulaciones que se tejen en simultáneo y que adquieren cierto grado de coherencia por medio de los diálogos de saberes y los procesos de traducción intercultural (Santos, 2010) que se dan en diferentes espacios-tiempos y escalas (Martínez-Torres \& Rosset, 2013; 2014; Rosset \& Martínez-Torres, 2012; 2016). En resumen, los $\mathrm{PCaC}$ constituyen un espacio primordial de construcción y articulación territorial, a la vez que de ensamblaje entre las dimensiones materiales e inmateriales de los territorios.

\section{Vector 3: la emergencia del campesinado agroecológico}

El campesinado tiene una larga y compleja historia de lucha. En la actualidad existe un movimiento amplio y muchos campos desde dónde se alimenta la (re)emergencia del campesinado como sujeto histórico-político. En este apartado nos enfocaremos en un dispositivo específico, los procesos $\mathrm{CaC}$, y un emergente particular, el campesinado agroecológico, para dar cuenta de cómo va tomando forma desde los procesos organizativos articulados en LVC. Los PCaC catalizan procesos territoriales y fortalecen la construcción de un sujeto social que articula múltiples dimensiones de la agroecología, tanto para la lucha, como para la producción y reproducción de la vida cotidiana ${ }^{8}$.

Estamos ante un sujeto atravesado por la mundialización de la lógica del capital y su avance sobre los territorios, las nuevas tecnologías -principalmente de información y comunicacióny un importantísimo nivel de organización y articulación política y territorial supralocal. Todo ello contribuye a la configuración de un meta-sujeto como un dispositivo de constitución de referentes de pertenencia más incluyentes (Zemelman, 2010), dónde lo político emerge como una cualidad de la agroecología como marco de movilización (LVC, 2011; 2012; 2013; 2015; 2016; Rosset \& MartínezTorres, 2016).

Sugerimos aquí que los procesos $\mathrm{CaC}$ actúan como dispositivo y locus de (re)construcción colectiva de subjetividades; como espacio

\footnotetext{
${ }^{8}$ Si bien existe una enorme diversidad de prácticas productivas, tradiciones culturales y particularidades ecológicas, podemos delinear algunas características generales del campesinado agroecológico emergente dentro de LVC. Por supuesto, no todos las(os) campesinas(os) contienen todas las características, pero en conjunto cubren una enorme variedad de rasgos agroecológicos. Entre ellos destacamos: producción familiar y/o comunitaria en pequeña escala; diseño de agroecosistemas sustentables y resilientes; alta diversidad e intercalamiento de cultivos; utilización de recursos recolectados y/o producidos localmente; preparación y utilización de abonos orgánicos; uso de repelentes naturales y control biológico de plagas; alto nivel de integración y sinergia entre sistemas productivos; alta eficiencia energética; escaso o nulo uso de insumos químicos sintetizados y/u otros productos extralocales; alto grado de organización y asociatividad (colectiva, comunal, cooperativa, etcétera); prácticas de intercambio, cooperación y reciprocidad; áreas de producción colectiva; espacios de formación y transmisión de saberes; entre muchas otras (Von der Weid, 2000; Holt-Giménez, 2001; Pachicho \& Fujisaka, 2004; Altieri \& Koohafkan, 2009; Altieri \& Nicholls, 2008; 2012; Perfecto et al., 2009; Machín Sosa et al., 2010; Rosset et al., 2011; Val, 2012; Rosset \& Martínez-Torres, 2013; Da Silva, 2014; Gliessman, 2015, 2018; Rosset \& Altieri, 2017; Rosset \& Val, 2018).
} 
donde se elaboran y socializan esos discursos, representaciones y prácticas desde las epistemes campesinas (Rosset \& Martínez-Torres, 2012). El lugar -no como espacio físico, sino como campo (Bourdieu, 1998)- en el que emergen y se comparten un conjunto de significaciones en torno a la agroecología como alternativa de producción y de vida. Un ámbito de confianza donde esas formas de ser-estar tienen un lugar de expresión, y el potencial transformador se va abriendo paso hacia lo real-concreto. En los PCaC el campesinado agroecológico toma forma en los cuerpos y mentes de quienes participan activamente del proceso, convirtiéndose en una fuerza material. No es un espacio exclusivo, pero sí importante para la emergencia del sujeto político campesino.

Los PCaC funcionarían como correa de transmisión en el circuito local-global de construcción de subjetividades. Allí se puede observar cómo y de qué manera se da ese ensamblaje en dos sentidos: 1) en un movimiento "centrípeto" donde se organizan y fortalecen sujetos locales; y 2) uno "centrífugo", en la construcción de un meta-sujeto campesino que contiene y abre espacio para la existencia de los proyectos locales. La articulación de diferentes sujetos locales alimenta la constitución del metasujeto global -desde el uso consciente de un esencialismo estratégico (Spivak, 1987)- diseñado para la disputa en una arena diferente a los espaciostiempos locales; una instancia global que a la vez le permite "bajar" herramientas de defensa a sus territorios.

Al mismo tiempo, los PCaC ofrecen modelos de referencia y marcos movilizadores más flexibles y equitativos. La organización desde este tipo de estructuras no totalmente jerárquicas favorece las prácticas políticas desjerarquizantes (Rocheleau,
2015). Las experiencias y praxis desde grupos no dominantes pueden contribuir a generar formas no dominantes de organización política y social. $\mathrm{CaC}$ fortalece, además, procesos autónomos y reduce la dependencia de instituciones y Estados, disminuyendo el riesgo de burocratización y cooptación de la agroecología por parte de los poderes dominantes (Giraldo \& Rosset, 2018; Giraldo \& McCune, en este volumen).

En los $\mathrm{PCaC}$ se van tejiendo las redes de construcciones alternativas. Son espacios en los que se recrea la mística solidaria, se refuerzan valores comunes y se construye progresivamente una conciencia colectiva para la movilización social hacia la transformación (LVC, 2011a; 2012; 2013; 2015; 2016; Rosset \& Martínez-Torres, 2012; 2016). Son, asimismo, espacios para la (re) emergencia de cosmovisiones y territorialidades ancestrales, actualizados en diálogo con saberes contemporáneos (Martínez-Torres \& Rosset, 2010; 2013), donde innovaciones y repertorios existentes se recombinan generando nuevas alternativas en el "arte de cultivar y habitar la tierra" (Giraldo, 2014; 2018).

Si el capital aparece como un sistema de dominación múltiple (Valdés 2009), el proyecto político campesino se estructuraría como un dispositivo de emancipación múltiple: es decir, un proyecto alterno de vida desde una nueva relación entre seres humanos -en términos de equidad y complementariedad de género, de no explotación, de solidaridad, de comunidad y comunalidad-, y entre seres humanos y naturaleza -coexistencia y coproducción- (Desmarais, 2007; Van der Ploeg, 2008; LVC, 2011a; 2012; 2013; 2015; 2016; Martínez-Torres \& Rosset, 2013; Rosset \& Martínez-Torres, 2016). 
Este fenómeno también puede pensarse en los términos planteados en el dispositivo 2, es decir, en la construcción de una territorialidad inmaterial común para defender la territorialidad material concreta, los espacios-tiempos de vida campesina. La construcción de este sujeto campesino es un dispositivo para la disputa en los territorios inmateriales, un artefacto para la disputa de sentidos. El sujeto político campesino pone un cerco, un dique de contención para proteger los territorios del avance del capital (Rosset, 2009), que permite la existencia y reexistencia de la diversidad campesina e indígena (y de la biodiversidad y los bienes comunes) (Leff, 2014; Fernandes, 2017). Es un dispositivo de defensa territorial en el marco de la cuarta guerra mundial, la guerra contra los pueblos y por la tierra y el territorio (Marcos SCI, 2017; Rosset, 2009).

\section{La importancia de los PCaC en La Vía Campesina para la masificación de la agroecología}

Es indiscutible la crisis sistémica, en particular socioambiental y agroalimentaria, por la que está atravesando la humanidad (Hoetmer, 2009; Rosset, 2009; Giraldo, 2014; 2018). La agroecología, la lucha por la soberanía alimentaria, y la búsqueda de la sustentabilidad representan una alternativa al modelo de producción hegemónica, y articulan en torno a ella una comunidad epistémicopolítica de lucha para la disputa del modelo de producción agroalimentaria, hoy dominada por la lógica del capitalismo financiero de los imperios agroalimentarios (Van der Ploeg, 2008; 2010).

Ante el avance del capital sobre territorios hasta hace no mucho tiempo considerados "marginales", las(os) campesinas(os), indígenas y otras(os) habitantes rurales representan la principal frontera de resistencia contra el hidro-agro-extractivismo de las megacorporaciones trasnacionales (Desmarais, 2007; Borras et al., 2008; Martínez-Torres \& Rosset, 2008; 2013; LVC, 2011a; 2012; 2013; 2015; 2016; Rosset \& Martínez-Torres, 2012; 2016). Así, en esta coyuntura el campesinado (re)emerge en la resistencia, actualizando su enorme potencial como sujeto histórico-político radical y revolucionario (Barbosa, 2013; 2016) ${ }^{9}$.

El campesinado actual forja en LVC su máximo nivel de articulación supranaciona $1^{10}$. Con territorios simbólicos ampliados, con alta capacidad organizativa y de movilización, y con proyectos políticos y sociales propios, las organizaciones políticas nacionales, regionales e internacionales han ido conformando un movimiento campesino global de unidad en la heterogeneidad, siendo

\footnotetext{
${ }^{9}$ Es importante recalcar que cuando hablamos del rol de los PCaC en la configuración de un sujeto político campesino, lo hacemos siempre dentro de los procesos de LVC y de ninguna manera hacemos referencia a una categoría extensible a todo el campesinado. Además, no pensamos al campesinado agroecológico como el sujeto político revolucionario, sino como un sujeto con reivindicaciones específicas y agenda propia, pero articulado en un gran frente de lucha con otros sectores sociales: feminismos, organizaciones indígenas, movimientos sociales rurales y urbanos, trabajadores precarizados, movimientos sindicales, movimientos por la diversidad sexual, entre muchos otros.

${ }^{10} \mathrm{El}$ dispositivo $\mathrm{PCaC}$ al que venimos haciendo referencia articula una gran diversidad de sectores: campesinos, agricultores de pequeña escala, trabajadores sin tierra, trabajadores rurales, pueblos indígenas, cazadores y recolectores, pescadores artesanales, pueblos pastores y trashumantes, pueblos de los bosques, ribereños y costeros, entre otros, que se autoadscriben al movimiento campesino internacional (Martínez-Torres \& Rosset, 2008; LVC, 2009; 2013). Los PCaC abren ese campo de diálogo para ir conformando un movimiento campesino global de unidad en la diversidad (Rosset \& Martínez-Torres, 2013; Martínez-Torres \& Rosset, 2014).
} 
esa diversidad de modos, luchas y estrategias una de sus principales fortalezas (Desmarais, 2007; Martínez-Torres \& Rosset, 2008; 2010; Rosset \& Martínez-Torres, 2016). La agroecología como defensa, resignificación y actualización de los modos de vida campesinos, es central en la disputa material y simbólica por la tierra y el territorio (Rosset, 2009; 2013).

Como hemos señalado, los $\mathrm{PCaC}$ son centrales para tejer esa unidad, consolidar el proyecto político campesino y promover la masificación de la agroecología como un proyecto alternativo de producción y de vida. En estos procesos se ensamblan todas las dimensiones antes descritas y los vectores analíticamente disgregados actúan en simultáneo, como un solo mecanismo sistémico. Revisemos brevemente algunos ejemplos concretos del funcionamiento de los procesos $\mathrm{CaC}$ como dispositivo dentro de LVC.

Los procesos de $\mathrm{CaC}$ son también importantes en la implementación de programas y estrategias de masificación (scaling up). En los $\mathrm{PCaC}$ se analizan y elaboran objetivos y procedimientos, favoreciendo de esta forma un intercambio más fluido con los diferentes aliados (movimientos sociales, universidades, ONG) e instituciones (Estados, gobiernos locales, FAO) (Altieri \& Nicholls, 2008; 2012; Rosset \& Altieri, 2017; Giraldo \& Rosset, 2018).

Reconocemos claramente que en el proceso de masificación de la agroecología intervienen diferentes y diversos agentes, pero en este trabajo centramos nuestra mirada en el campesinado agroecológico dentro de LVC. En nuestro parecer, el campesinado agroecológico es una figura central en el proceso de transformación agroecológica, en tanto demanda e incentiva el involucramiento de otros sectores en este proceso. Pensemos por ejemplo en el rol activo que tuvo en la emergencia de nuevos programas institucionales como el Global Scaling Up Agroecology Initiative de la FAO (FAO, 2018a; 2018b), o en la demanda e implementación de políticas públicas para el escalamiento de la agroecología en diversos países ${ }^{11}$, así como en la "Declaración sobre los derechos de los campesinos y otras personas que trabajan en las zonas rurales" recientemente adoptada por la Asamblea General de las Naciones Unidas (ONU, 2018).

Tomemos un ejemplo reciente, el 2nd International Symposium on Agroecology: Scaling Up Agroecology to Achieve the Sustainable Development Goals (SDGs), organizado por la FAO en abril de $2018^{12}$. Allí LVC logró construir un marco de alianzas estratégicas (y hegemonía) para llevar como sociedad civil una posición común y disputar sentidos ante el organismo, los Estados y los representantes del agronegocio. Este es un caso claro de cómo se ha ido construyendo un dispositivo específico para la disputa, logrando diferenciar la agroecología campesina de los intentos de cooptación por parte del agronegocio en su reconversión verde (FAO, 2018a; 2018b; Giraldo \&

\footnotetext{
${ }^{11}$ Solo por mencionar algunos casos relevados en los últimos años: Brasil (Sauer \& Mészáro, 2017; Schmitt et al., 2017), Bolivia (Sabourin et al., 2017; Webber, 2017), Cuba (Machín Sosa et al., 2010; Vázquez et al., 2017), India (Khadse et al., 2017; Kumar, 2017; Kahdse \& Rosset, en este volumen), Mali (Beauregard 2009), Nicaragua (Freguin-Gresh, 2017), Venezuela (Sabourin et al., 2017; Domené \& Herrera, en este volumen), entre otros. Para un análisis crítico sobre los límites de los procesos institucionales y las políticas públicas, véase Giraldo \& Rosset (2018) y Giraldo \& McCune, en este volumen.

${ }^{12} \mathrm{http} / /$ www.fao.org/about/meetings/second-international-agroecology-symposium/es/
} 
Rosset, 2018). El impacto real que pueda tener esa presencia tendrá que ser evaluada críticamente, pero el solo hecho de que el campesinado esté sentado en la mesa de discusión representa un relativo avance, ganado a fuerza de lucha organizada (MartínezTorres \& Rosset, 2010) ${ }^{13}$.

Si bien desde LVC se reconoce la importancia de desarrollar una estrategia de cabildeo y disputa institucional, no es ese el eje medular del proyecto político, cuyo centro de gravedad está en los territorios y procesos organizativos locales (Martínez-Torres \& Rosset, 2010). La reflexión desde los movimientos sociales conduce a la necesidad de incrementar los grados de autonomía -territorial, alimentaria, productiva, política, etcétera- para consolidar el proyecto político campesino. La disputa central es en y desde los territorios, en la consecución de la soberanía alimentaria, la reforma agraria popular y la agroecología como forma de producción y de vida (Rosset, 2013; Da Silva, 2014; Giraldo \& Rosset, 2018).

Importante en este sentido es la "Campaña Global de Semillas como Patrimonio de los Pueblos y al Servicio de la Humanidad", cuyo objetivo es contrarrestar la concentración y privatización de las semillas (LVC, 2010; 2011b; 2011c). Esta campaña articula diferentes territorios y luchas, con las mujeres como protagonistas de todo el proceso (LVC, 2011a; 2011c; 2018). La disputa por los bienes comunes es fundamental para la reproducción del campesinado, y en ella se puede observar la dialéctica local-global que, argumentamos, se construye y estructura en los PCaC promovidos por LVC.

Otro ejemplo destacado es el caso del Feminismo Campesino Popular. Si bien el patriarcado es un fenómeno generalizado, las condiciones específicas de la violencia estructural en el campo son diferentes a las de las urbes (Rocheleau et al., 1996; Siliprandi \& Zuluaga, 2014). Las mujeres del campo vienen desarrollando acciones y una serie de reflexiones teóricas que interpelan críticamente el statu quo y revelan cómo se manifiesta el patriarcado en sus territorios, a fin de desarticular los mecanismos de dominación y transformar las condiciones de opresión en las que viven las mujeres rurales (LVC, 2007; 2011b; 2017; Siliprandi \& Zuluaga, 2014; Seibert, 2017). Es un proceso potente en el que las mujeres rurales articulan su reivindicación antipatriarcal con la lucha de clases, la lucha por la tierra y el territorio, con las semillas y los bienes comunes.

El feminismo campesino y popular ha venido a renovar y reforzar la propuesta agroecológica dentro de LVC, con la suma de un elemento esencial para la construcción de un nuevo y diferente proyecto social. Las mujeres rurales están traccionando al campesinado a convertirse en protagonista de esta transformación histórica, en este cambio de época hacia la construcción de sociedades pospatriarcales y poscapitalistas (LVC, 2007; Seibert, 2017) ${ }^{14}$.

\footnotetext{
${ }^{13}$ Véase la "Declaración de organizaciones de productores y productoras de alimentos a pequeña escala y organizaciones de la sociedad civil en el II simposio internacional sobre agroecología convocado por la FAO” de abril de 2018.

${ }^{14}$ A este importante aporte se le ha sumado recientemente la visibilización y reivindicación de las diversidades sexuales en el mundo rural. Un importante movimiento LGTBIQ+ está emergiendo (particularmente en Latinoamérica) para añadir este nuevo clivaje al proyecto político campesino. Si bien es algo reciente y no aparece claramente en todas las regiones, creemos que en corto tiempo será un elemento muy importante y dinámico en la construcción de alternativas de vida desde LVC.
} 
Igualmente, importa prestar atención a la participación de las(os) jóvenes rurales. Los procesos formativos territoriales ya se perfilan como la herramienta principal para la formación de sujetos críticos en el campo, así como en la estrategia central para la disputa de sentidos (productivos, culturales, identitarios, etcétera) en el mundo rural (Caldart, 2004; Barbosa, 2013; McCune et al., 2014; 2016; Barbosa \& Rosset, 2017). El énfasis en el recambio generacional y el fortalecimiento del trabajo con jóvenes representa una de las principales apuestas políticas de LVC, y es el tema central de nuestra segunda contribución (véase Rosset et al., en este volumen).

En definitiva, al interior de LVC, $\mathrm{CaC}$ ha trascendido su carácter metodológico para convertirse en un dispositivo para la transformación agroecológica, la articulación de territorios y la constitución de un sujeto histórico movilizador del proyecto político campesino, con el objetivo de alcanzar la transformación de los sistemas agroalimentarios, las diversas condiciones de opresión (de clase, patriarcales, étnicas, etcétera) y, en el largo plazo, la construcción de un reordenamiento de las relaciones sociales y ambientales globales en un nuevo paradigma de vida.

En estos casos, así como en varios otros procesos impulsados por LVC, la masificación de la agroecología es fundamental. Para el proyecto sociopolítico de LVC, masificar la agroecología no solo es esencial para la disputa con el agronegocio y el sistema del capital como ordenador hegemónico de las relaciones socioambientales, sino que se perfila, además, como la principal vía para la transformación social y ambientalmente sustentable de los sistemas agroalimentarios. En resumen, masificar la agroecología implica la expansión y territorialización del proyecto alternativo que se viene gestando desde el movimiento campesino internacional; un proyecto político de transformación profunda del sistema agroalimentario, las relaciones sociales, y entre seres humanos-naturaleza hacia un paradigma civilizatorio por fuera de los marcos de la modernidad hegemónica, el patriarcado y la lógica del capital.

\section{Agradecimientos}

Agradecemos a las(os) compañeras(os) de La Vía Campesina, la CLOC-VC y la Asociación Nacional de Agricultores Pequeños (ANAP) de Cuba y, en particular, a las(os) guajiras(os) cubanas(os) de quienes hemos aprendido tanto. V. Val desea agradecer al pueblo de México que, a través del Conacyt, financió parcialmente de esta investigación. P. Rosset desea agradecer a la FUNCAP-CAPES por la beca PVE en la Universidade Estadual do Ceará. 


\section{Referencias}

Altieri, M. A. Agroecology: principles and strategies for designing sustainable farming systems. Agroecology in action. NY: Hayworth Press, 2000.

Altieri, M. A.; Koohafkan, P. Enduring farms: Climate change, smallholders and traditional farming communities. Penang: Third World Network, 2009.

Altieri, M. A.; Nicholls, C. Scaling up agroecological approaches for food sovereignty in Latin America. Development, 51(4), 472-480, 2008.

Altieri, M. A.; Nicholls, C. Agroecology scaling up for food sovereignty and resiliency. Sustainable Agriculture Reviews, 11, 1-29, 2012.

Altieri, M. A.; Toledo, V. M. The agroecological revolution in LatinAmerica: rescuing nature, ensuring food sovereignty and empowering peasants. Journal of Peasant Studies, 38(3), 587-612, 2011.

ANAP - Asociación Nacional de Agricultores Pequeños. En: Anales del XXII Congreso de la Asociación Nacional de Agricultores Pequeños de Cuba. La Habana: ANAP, 2020.

Barbosa, L. P. Educación, movimientos sociales y estado en América Latina: estudio analítico de las experiencias de resistencia contra-hegemónica en Brasil y México. Ciudad de México. Tesis de Doctorado en Estudios Latinoamericanos - UNAM, 2013.

Barbosa, L. P. Educação do Campo [education for and by the countryside] as a political project in the context of the struggle for land in Brazil. The Journal of Peasant Studies, 44(1),118-143, 2016.

Barbosa, L. P.; Rosset, P. M. Movimentos sociais e educação do campo na américa latina: aprendizagens de um percurso histórico. Revista Práxis Educacional, Vitória da Conquista, 13(26), 22-48, 2017.

Beauregard, S. Food policy for people: incorporating food sovereignty principles into State governance: case studies of Venezuela, Mali, Ecuador, and Bolivia, 2009.
Disponible en: <http://www.oxy.edu/sites/default/files/ assets/UEP/Comps/2009/Beauregard\%20Food\%20 Policy\%20for\%20People.pdf/>. Acceso en: jul. 2020.

Boege, E.; Carranza., T. Agricultura sostenible campesinoindígena, soberanía alimentaria y equidad de género. Seis experiencias de organizaciones indígenas y campesinas en México, Programa de Intercambio, Diálogo y Asesoría en Agricultura Sostenible y Soberanía Alimentaria, PIDAASSA. México: PIDAASSA, 87-139, 2009.

Borras, S. M.; Edelman, M.; Kay, C. Transnational agrarian movements: origins and politics, campaigns and impact. Journal of Agrarian Change, 8(2-3), 169-204, 2008.

Bourdieu, P. Practical reason: on the theory of action. Palo Alto: Stanford University Press, 1998.

Brescia, S. Fertile ground: scaling agroecology from the ground up. Oakland: Food First/Institute for Food and Development Policy, 2017.

Bussolini, J. What is a dispositive? Foucault Studies, 10, 85-107, 2010.

Caldart, R. S. Pedagogia do Movimento. São Paulo: Expressão Popular, 2004.

Calle Collado, A.; Gallar, D. Agroecología Política: transición social y campesinado. In: Anales del VIII Congreso Latinoamericano de Sociología Rural. Porto de Gailnhas, 15-19 nov., 2010.

Da Silva, V. I. Clase campesina. Modo de ser, de vivir y de producir. Porto Alegre: Instituto Cultural Padre Jósimo, 2014.

De Schutter, O. United Nations Special Rapporteur on the Right to Food, Briefing Note 01. Countries tackling hunger with a right to food approach. Significant progress in implementing the right to food at national scale in Africa, Latin America and South Asia, 2010.

Deleuze, G. Post-scriptum sobre las sociedades de control. Polis, Revista Latinoamericana, 5(13), 277-286, 2006. 
Desmarais, A. La Via Campesina. Globalization and the power of peasants. Halifax, Londres: Fernwood Publishing; Pluto Press, 2007.

Doimeadios Reyes, Y. Situación económica actual: algunas reflexiones. Revista América Latina 465:7-10, 2011.

Escobar, A. The invention of development. Current History, 98(631), 382-387, 1999.

Escobar, A. El 'postdesarrollo' como concepto y práctica social. In: Mato, D. Políticas de economía, ambiente y sociedad en tiempos de globalización. Caracas: Universidad Central de Venezuela, p. 17-31, 2005.

Escobar, A. Territorios de diferencia: Lugar, movimientos, vida, redes. Popayán: Envión, 2010.

FAO - Food and Agriculture Organization of the United Nations. Scaling up agroecology initiative: transforming food and agricultural systems in support of the SDGs. In: A proposal prepared for the International Symposium on Agroecology. Rome, 3-5 abr., 2018a. Disponible en: <http:// www.fao.org/3/I9049EN/i9049en.pdf>. Acceso en: sept., 2020 .

FAO - Food and Agriculture Organization of the United Nations. In: 2nd International Symposium on Agroecology: scaling up agroecology to achieve the sustainable development goals (SDGs). Rome, 3-5 abril de 2018, Roma, 2018b.

Ferguson, B. G. Editorial: Agroecology as a transformative transdiscipline. Ciência \& Tecnologia Social, 2(1), 3-7, 2015. Disponible en: http://periodicos.unb.br/index.php/ cts/article/view/20033/14196

Fernandes, B. M. Sobre a tipología de territorios. In: Saquet, M. A.; Sposito, E. S. (Edits.). Territórios e territorialidades: teoria, processos e conflitos. São Paulo, Expressão Popular, 197-216, 2009.

Fernandes, B. M. Territorios y Soberanía Alimentaria. ReLaER, II(3), 22-39, 2017.

Figueras Matos, D. Innovación social y desarrollo local. Potencialidades y limitaciones de los gobiernos locales para la promoción del desarrollo. Documentación y sistematización de experiencias. Santa Clara: Unversidad Central de Las Villas "Marta Abreu”, 2005.
Foucault, M. El orden del discurso. Buenos Aires: Tusquets Editores, 1992.

Foucault, M. Defender la sociedad: curso en el Collège de France (1975-1976). Buenos Aires: Fondo de Cultura Económica, 2000.

Freguin-Gresh, S. Agroecología y agricultura orgánica en Nicaragua. Génesis, institucionalización y desafíos. In: Sabourin, E. et al. (Eds.). Políticas públicas a favor de la agroecología en América Latina y El Caribe. Brasilia: FAO; Red PP-AL, 311-350, 2017.

García Fanlo, L. ¿Qué es un dispositivo?: Foucault, Deleuze, Agamben. A Parte Rei. Revista de Filosofia, 1-8, 2011.

Giddens, A. Sociology: a brief but critical introduction. Basingstoke: Palgrave Macmillan, 1986.

Giraldo, O. F. Utopías en la era de la supervivencia. Una interpretación del Buen Vivir. Ciudad de México: Itaca, 2014.

Giraldo, O. F. Convivialidad y agroecología. En: Street, S. Con ojos bien abiertos: ante el despojo, rehabilitemos lo común. Guadalajara, México: CIESAS, 2016.

Giraldo, O. F. Ecología política de la agricultura. Agroecología y posdesarrollo. San Cristóbal de Las Casas: El Colegio de la Frontera Sur, 2018.

Giraldo, O. F.; Rosset, P. M. Agroecology as a territory in dispute: between institutionality and social movements. The Journal of Peasant Studies, 45(3), 545-564, 2018.

Gliessman, S. R. Agroecology: the ecology of sustainable food systems. New York: Taylor and Francis, 2007.

Gliessman, S. R. Agroecology: the ecology of sustainable food systems. Boca Raton: CRC Press/Taylor \& Francis, 3. ed., 2015.

Gliessman, S. Scaling-out and scaling-up agroecology. Agroecology and Sustainable Food Systems, 42(8), 841-842, 2018. doi: $10.1080 / 21683565.2018 .1481249$

Gonsalves. J. F. Going to scale: what we have garnered from recent workshops. LEISA Magazine, 17(3), 6-10, 2001. Disponible en: http://www.agriculturesnetwork.org/ library/63894 
González Mastrapa, E.; Susset Pérez, A. Desarrollo rural, descentralización y articulación de actores. La experiencia del desarrollo agrario municipal en Cuba. Revista ALASRU, Análisis Latinoamericano del Medio Rural, (5), 209-233, 2010.

Haesbaert, R. El mito de la desterritorialización. Del “fin de los territorios" a la multiterritorialidad. Ciudad de México. Siglo XXI Editores, 2011.

Haesbaert, R. Del mito de la desterritorialización a la multiterritorialidad. Cultura y Representaciones Sociales, 8, 9-42, 2013.

Harvey, D. La condición de la postmodernidad. Investigación sobre los orígenes del cambio cultural. Buenos Aires: Amorrortu, 1998.

Harvey, D. El nuevo imperialismo. Madrid: Akal, 2004.

Hoetmer, R. Repensar la política desde América Latina. Cultura, Estado y movimientos sociales. Lima: Universidad Mayor de San Marcos, 2009.

Holt-Giménez, E. Scaling up sustainable agricultura. Lessons from the Campesino a Campesino movement. LEISA magazine, 17(3), 27-29, 2001.

Holt-Giménez, E. Campesino a Campesino: voices from Latin America's Farmer to Farmer Movement for sustainable agriculture. Oakland: Food First Books, 2006.

Khadse, A; Rosset, P. M.; Morales, H; Ferguson, B. G. Taking agroecology to scale: the Zero Budget natural farming peasant movement in Karnataka, India. The Journal of Peasant Studies, 45, 1-28, 2017

Kohlmans, E. Construyendo procesos "De Campesino A Campesino”. Lima: Espigas y Pan Para El Mundo, 2006.

Kumar, T. V. A. P. Govt initiative of climate resilient 'Zero Budget' natural farming (ZBNF) for enhancing farm livelihoods, food security, and restoring soil health, 2017. Disponible en: <http://www.mcrhrdi.gov.in/92fc/ week8/27thOct-a.pzbnfexperience-final.pdf $>$. Acceso en: ago., 2020.

LVC - La Vía Campesina. Comprender el feminismo en la lucha campesina, 2007. Disponible en: <https:// viacampesina.org/es/comprender-feminismo-la-luchacampesina/>. Acceso en: jul., 2020.

LVC - La Vía Campesina. La Via Campesina policy documents, 2009. Disponible en: $<$ https:// viacampesina. org/en/la-via-campesina-policy-documents/>. Acceso en: jul., 2020.

LVC - La Vía Campesina. Reunión de la campaña de semillas CLOC-Vía Campesina, Quito, 2010. Disponible en: $<$ https://viacampesina.org/es/reunion-campana-semillascloc-via-campesina/>. Acceso en: jun., 2020.

LVC - La Vía Campesina. La agricultura campesina sostenible puede alimentar al mundo, 2011a. Disponible en: $<$ https://viacampesina.org/es/publicaciones-mainmenu30/1117-la-agricultura-campesina-sostenible-puedealimentar-al-mundo>. Acceso en: http://viacampesina.org/ downloads/pdf/sp/paper6-ES-FINAL.pdfAcceso en: ago., 2020 .

LVC - La Vía Campesina. Las semillas campesinas son dignidad, cultura y vida: campesinos en resistencia, defendiendo sus derechos respecto de las semillas campesinas. Bali Declaración sobre Semillas, 2011b. Disponible en: $<$ https://www.servindi.org/actualidad/45139>http://www. inesc.org.br/noticias-es/2011/marzo/bali-declaracion-sobresemilla. Acceso en: ago., 2020.

LVC - La Vía Campesina. Declaración de Shashe. In: Primer encuentro de formadores@s en agroecología en la región 1 de África de La Vía Campesina, Masvingo, Zimbabue, 12-20 jun., 2011c Disponible en: <https://viacampesina. org/es/primer-encuentro-de-formadoress-en-agroecologiaen-la-region-1-de-africa-de-la-via-campesina/>http:// viacampesina.org/es/index.php/temas-principalesmainmenu-27/reforma-agraria-mainmenu-36/1205-primerencuentro-de-formadoress-en-agroecologia-en-la-region1-de-africa-de-la-via-campesinaAcceso en;Acce. Acceso en: ago., 2020.

LVC - La Vía Campesina. Declaración de Bukit Tinggi sobre la reforma agraria en el siglo XXI, 2012. Disponible en: <https://viacampesina.org/es/declaracionde-bukit-tinggi-sobre-la-reforma-agraria-en-el-sigloxxi/>http://viacampesina.org/en/index.php/main-is-sues- 
mainmenu-27/agrarian-reform-mainmenu-36/1281-bukittinggi-declaration-on-agrarian-reform-in-the-21 st-century. Acceso en: ago., 2020.

LVC - La Vía Campesina. De Maputo a Yakarta: 5 años de agroecología en La Via Campesina, 2013. Disponible en: $<$ http://viacampesina.org/downloads/pdf/es/De-Maputo-aYakarta-ES-web.pdfhttps://viacampesina.org/es/de-maputoa-yakarta-5-anos-de-agroecologia-en-la-via-campesina/ $>$. Acceso en: ago., 2020.

LVC - La Vía Campesina. La Via Campesina Declaration of the international forum for agroecology, 2015. Disponible en: $<$ http://viacampesina.org/en/index.php/main-825issuesmainmenu-27/sustainable- peasants-agriculture-mainmenu42/1749-declaration-of-the-international-forum-foragroecology $>$. Acceso en: jul., 2020.

LVC - La Vía Campesina. International Conference of Agrarian Reform: Marabá Declaration, 2016. Disponible en: https://viacampesina.org/en/international-conferenceof-agrarian-reform-declaration-of-maraba1/ Acceso en: sept., 2020.

LVC - La Vía Campesina. Declaration of güira de melena: first global encounter of la via campesina agroecology schools and formation processes, 2018. Disponible en: $<$ https:/viacampesina.org/en/declaration-of-guira-demelena-first-global-encounter-of-la-via-campesinaagroecology-schools-and-formation-processes/>. Acceso en: jun., 2020.

Leff, E. La apuesta por la vida. Imaginación sociológica e imaginarios sociales en los territorios ambientales del sur. Ciudad de México: Vozes Editora, 2014.

Machín Sosa, B.; Roque Jaime, A.; Ávila Lozano, D.; Rosset, P. M. Revolución Agroecológica. El Movimiento Campesino a Campesino de la ANAP en Cuba. Ciudad de México: ANAP-La Vía Campesina, 2010.

Marcos, SCI. 7 piezas sueltas en el rompecabezas mundial. In: Rodríguez Lascano, S. (Comp.). Escritos sobre la guerra y la economía política. México: Pensamiento Crítico Ediciones, 101-134, 2017.

Martínez-Torres, M. E.; Rosset, P. M. La Via Campesina: transnationalizing peasant struggle and hope. In: StahlerSholk, R.; Vanden, H. E.; Kuecker, G. D. (Edits.). Latin american social movements in the twenty-first century: resistance, power, and democracy. Maryland: Rowman \& Littlefield, 101-134, 2008.

Martínez-Torres, M. E.; Rosset, P. M. La Via Campesina: The birth and evolution of a transnational social movement. Journal of Peasant Studies, 37(1), 49-175, 2010.

Martínez-Torres, M. E.; Rosset, P. M. Del conflicto de modelos para el mundo rural emerge la vía campesina como movimiento social transnacional. El Otro Derecho, 44(Luchas agrarias en América Latina), 21-57, 2013.

Martínez-Torres, M. E.; Rosset, P. M. Diálogo de saberes in La Vía Campesina: Food sovereignty and agroecology. Journal of Peasant Studies, 41(6), 979-997, 2014.

McCune, N.; Reardon, J.; Rosset, P. M. Agroecological formación in rural social movements. Radical Teacher, 98, 31-37, 2014.

McCune, N.; Rosset, P. M.; Cruz, T.; Saldívar, A.; Morales, H. Mediated territoriality: rural workers and the efforts to scale out agroecology in Nicaragua. The Journal of Peasant Studies, 44(2), 354-376, 2016.

Merlet, M. Cambios en la política agraria en Cuba. Redistribución de tierras a gran escala a productores individuales. Los Estudios de AGTER, 4, 2011.

Mier y Terán, M. G.; Giraldo, O. F.; Aldasoro, M.; Morales, H; Ferguson, B.; Rosset, P. M.; Khadse, A.; Campos, C. Bringing agroecology to scale: key drivers and emblematic cases. Agroecology and Sustainable Food Systems, 42(6), 637-665, 2018.

ONU - Organización de las Naciones Unidas. United nations declaration on the rights of peasants and other people working in rural areas, 2018. Disponible en: $<$ https:// undocs.org/en/A/C.3/73/L.30>. Acceso en: jun., 2020.

Pachicho, D.; Fujisaka, S. Scaling up and out: achieving widespread impact through agricultural research. Cali: Centro Internacional de Agricultura Tropical, 2004.

Parmentier, S. Scaling-up agroecological approaches: what, why and how? Bruselas: Oxfam-Solidarity, 2014.

Pérez Rojas, N.; Echeverría León, D. Participación y producción agraria en Cuba. Las UBPC. Revista Temas, (11), 5-15, 1998. 
Perfecto, I.; Vandermeer, J. H.; Wright, A. L. Nature's matrix: linking agriculture, conservation and food sovereignty. Londres: Earthscan, 2009.

Porto-Gonçalves, W. La reinvención de los territorios. América Latina en movimiento, XXXIII (II Época), 2009.

Ramos, S. F. J. Grupo Vicente Guerrero de Españita, Tlaxcala, Dos décadas de promoción de campesino a campesino. México: Red de Gestión de Recursos Naturales. Fundación Rockefeller, Serie Estudios de Caso, 1998.

Rocheleau, D. Networked, rooted and territorial: green grabbing and resistance in Chiapas. Journal of Peasant Studies, 42(3-4), 695-723, 2015. doi:10.1080/03066150. 2014.993622

Rocheleau, D.; Thomas-Slayter, B.; Wangari, E. Feminist political ecology: global issues and local experiences. Londres: Routledge, 1996.

Rosset, P. M. La guerra por la tierra y el territorio. En: Anales del Primer Coloquio Internacional In Memoriam Andrés Aubry: planeta tierra: movimientos antisistémicos. San Cristóbal de Las Casas, 2009.

Rosset, P. M. Re-thinking agrarian reform, land and territory in La Via Campesina. Journal of Peasant Studies, 40(4), 721-775, 2013.

Rosset. P. M. Social organization and process in bringing agroecology to scale. En: Proceedings of Agroecology for food security and nutrition, Food and agriculture organization (FAO) of the United Nations. Rome, 18-19 sep., 2014. Rome: FAO, p. 298-307, 2015. Disponible en: http://www.fao.org/3/a-i4729e.pdf. Acceso en: jun., 2020.

Rosset, P. M.; Altieri, M. A. Agroecology: science and politics. Manitoba: Fernwood Publishing, 2017.

Rosset, P. M.; Machín Sosa, B.; Roque, A. M.; Ávila, D. R. The Campesino-to-Campesino agroecology movement of ANAP in Cuba: social process methodology in the construction of sustainable peasant agriculture and food sovereignty. Journal of Peasant Studies, 38(1), 161-191, 2011.

Rosset, P. M.; Martínez-Torres, M. E. Rural social movements and agroecology: context, theory, and process. Ecology and Society, 17(3), 1-17, 2012.
Rosset, P. M.; Martínez-Torres, M. E. La Via Campesina and agroecology. La Via Campesina's Open Book: Celebrating 20 Years of Struggle and Hope. Jakarta: LVC, 2013.

Rosset, P. M.; Martínez-Torres, M. E. Agroecología, territorio, recampesinización y movimientos sociales. Estudios Sociales. Revista de investigación cientifica, 25(47), 275-299, 2016.

Rosset, P. M.; Val, V. The 'Campesino a Campesino' Agroecology Movement in Cuba: food sovereignty and food as a commons. En: Vivero-Pol, J.L.; Ferrando, T.; De Schutter, O.; Mattei, U. Routledge handbook of food as a commons. Londres: Routledge, p. 251-265, 2018. doi: $10.4324 / 9781315161495$

Sabourin, E., Patrouilleau, M. M.; Vásquez, F. J.; Niederle, P. Políticas públicas a favor de la agroecología en América Latina y El Caribe. Porto Alegre: REd PP-Al-FAO, 2017.

Santos, B. D. S. Descolonizar el saber, reinventar el poder. Montevideo: Ediciones Trilce - Extensión universitaria Universidad de la República, 2010.

Sauer, S.; Mészáros, G. The political economy of land struggle in Brazil under Workers' Party governments. Journal of Agrarian Change, 17(2), 397-414, 2017.

Schmitt, C.; Niederle, P.; Ávila, M.; Sabourin, E.; Petersen, P.; Silveira, L.; Assis, W.; Palm J; Fernandes, G. B. G. La experiencia brasileña de construcción de políticas públicas en favor de la Agroecología. In: Sabourin, E. et al. Políticas públicas a favor de la agroecología en América Latina y El Caribe. Brasilia: FAO; Red PP-AL, p. 44-69, 2017.

Seibert, I. G. Feminismo campesino y popular feminismo campesino y popular. Una propuesta de las campesinas de Latinoamérica, 2017. Disponible en: <http://www. soberaniaalimentaria.info/numeros-publicados/60-numero29/454-feminismo-campesino-y-popular $>$. Acceso en: abr., 2020 .

Sevilla Guzmán, E. De la sociología rural a la agroecología. Bases ecológicas de la producción. Barcelona: Icaria, 2006.

Siliprandi, E.; Zuluaga, G.P. (Eds). Género, agroecología y soberanía alimentaria: perspectivas ecofeministas. Barcelona: Icaria, G.P., 2014. 
Spivak, G. In other worlds. Essays in Cultural Politics. New York: Methuen, 1987.

Svampa, M. Protesta, movimientos sociales y dimensiones de la acción colectiva en América Latina. Jornadas de Homenaje a Charles Tilly. Madrid: Universidad Complutense de Madrid-Fundación Carolina, 2009.

Tilly, C. From mobilization to collective action. USA: McGraw-Hill, 1978.

Val, V. Sembrando alternativas; cosechando esperanzas. (Re)campesinización agroecológica en las lomas del Escambray, Provincia de Villa Clara, Cuba. México: Centro de Investigaciones y Estudios Superiores en Antropología Social, 2012. doi: 10.13140/RG.2.2.29031.09129

Val, V. Hacer, conocer y ser. Agroecología en primera persona, 2017. Disponible en: $<$ https://sites.google.com/ site/agroecologiadesdesur/autores/el-cojo $>$. Acceso en: jul., 2020. doi: 10.13140/RG.2.2.35012.48003

Valdés Gutiérrez, G. Posneoliberalismo y movimientos antisistémicos. La Habana: Editorial de Ciencias Sociales, 2009.

Van der Ploeg, J. D. The new peasantries: struggles for autonomy and sustainability in an era of empire and globalization. London: Earthscan, 2008.

Van der Ploeg, J. D. The peasantries of the twenty-first century: the commoditization debate Revisited. Journal of Peasant Studies, 37(1), 1-30, 2010.
Vásquez Zeledón, J. I.; Rivas Espinoza, A. De campesino a campesino en Nicaragua. Managua: UNAG, 2006.

Vázquez, L. L.; Marzin, J.; González, N. Políticas públicas y transición hacia la agricultura sostenible sobre bases agroecológicas en Cuba. In: Sabourin, E. et al. Politicas públicas a favor de la agroecología en América Latina y El Caribe. Brasilia: FAO, Red PP-AL, 2017.

Von der Weid, J. M. Scaling up, and scaling further up: an ongoing experience of participatory development in Brazil. Sao Paulo: Assessoria e Serviços a Projectos em Agricultura Alternativa (AS-PTA), 2000. Disponible en: <http://www. fao.org/docs/eims/ upload/Q77 215152/AS-PTA.pdf>. Acceso en: jul., 2020.

Webber, J. R. Evo Morales, transformismo, and the consolidation of agrarian capitalism in Bolivia. Journal of Agrarian Change, 17(2), 330-347, 2017.

Zamora, C. Hacia la racionalidad liberadora en los movimientos sociales. Identidades y discontinuidades en un mundo donde quepan muchos mundos. In: Marañón, B. (Ed.). Más allá de la racionalidad instrumental: hacia el reencuentro con la reproducción de la vida y el respeto a la naturaleza. El Buen Vivir y la descolonialidad. México: UNAM, p. 60-77, 2014.

Zemelman, H. Sujeto y subjetividad: la problemática de las alternativas como construcción posible. Polis, 9(27), 355-366, 2010. 